Pamela Angle MD FRCPC DABA, Dorothy Thompson MB FRCPC, Stephen Halpern MD FRCPC MSc, Donna B. Wilson RN BSL BSCN MN

\title{
Second stage pushing correlates with headache after unintentional dural puncture in parturients
}

Purpose: To determine the association between bearing down, postdural puncture headache (PDPH) and epidural blood patch (EBP) following single 17 gauge unintentional dural puncture (UDP) in parturients.

Methods: The charts of 60 parturients identified with UDP in our institutional database during epidural placement were independently reviewed. Patients were divided into categories based on the anesthetic record: well-documented single punctures; well-documented multiple punctures; catheter-related puncture; unclear category (not clear if more than one puncture occurred or if dural puncture had occurred at all) and no evidence of dural puncture.

Patients with single 17 gauge punctures were divided into those who had pushed (Group I) and those who had not (Group 2). Group 2 patients had undergone Cesarean section before reaching second stage labour. The incidence of PDPH, EBP, and cumulative duration to delivery after UDP were compared between groups.

Results: Thirty-three patients with well-documented single punctures were identified: 23 had engaged in active pushing as part of second stage labour(Group 1); 10 had not (Group 2). Seventy-four percent of Group I developed PDPH compared with $10 \%$ in Group $2(P<0.002)$. Fifty-seven percent of Group I received an EBP compared with $0 \%$ in Group $2(P<0.002)$. Increasing the duration of pushing was associated with an increasing incidence of PDPH; the majority of women who pushed $>30$ min developed headache.

Conclusions: An increased incidence of PDPH and EBP after UDP occurs in women bearing down in 2nd stage labour when compared with those who never pushed. There was also an association between the cumulative duration of bearing down and the incidence of PDPH.

Objectif : Déterminer l'association qui existe entre les efforts expulsifs, les céphalées postponction durale (CPPD) et le colmatage sanguin épidural (CSE) à la suite d'une seule brèche durale accidentelle (BDA) au moyen d'un aiguille de calibre 17 chez des parturientes.

Méthode : On a révisé séparément 60 dossiers qui présentaient des BDA pendant la mise en place de l'aiguille épidurale. On a réparti les parturientes selon le protocole anesthésique : des ponctions uniques vérifiées; des ponctions multiples vérifiées; des ponctions avec cathéters; une catégorie imprécise, si plus d'une ponction a été réalisée ou si la ponction durale s'est produite à chaque essai; aucune preuve de ponction durale. Les patientes qui n'ont eu qu'une ponction avec une aiguille de calibre 17 ont été réparties en deux groupes: celles qui ont poussé (Groupe I) et celles qui n'ont pas poussé (Groupe 2), ayant subi une césarienne avant que le travail n'en soit à la période d'expulsion. L'incidence de CPPD et de CSE et le temps entre la naissance et la BDA ont fait l'objet de comparaisons intergroupes.

Résultats : Trente-trois patientes n'avaient reçu qu'une seule ponction : 23 s'étaient engagées à pousser activement pendant la phase d'expulsion du travail (Groupe 1); 10 ne poussaient pas (Groupe 2). Soixante-quatorze pour cent des patientes du Groupe 1 et $10 \%$ du Groupe 2 ont souffert de CPPD $(P<0,002)$. Cinquante-sept pour cent des patientes du Groupe I et $0 \%$ du Groupe 2 ont reçu un CSE $(P<0,002)$. Lincidence de CPPD a augmenté avec le temps des efforts expulsifs; la majorité des femmes qui ont poussé $>30$ min ont eu des céphalées.

Conclusion : Une plus grande incidence de CPPD et de CSE a suivi la survenue d'une BDA chez des parturientes qui ont poussé à la période d'expulsion du travail comparées aux femmes qui ont subi une césarienne. Lincidence des CPPD est aussi liée au temps des efforts expulsifs.

From the Sunnybrook and Women's College Health Sciences Center (Women's College Hospital Campus), University of Toronto, Toronto, Ontario, Canada.

Address correspondence to: Dr. P. Angle, Department of Anesthesiology, Women's College Hospital Campus, Sunnybrook and Women's College Health Sciences Center, 76 Grenville Street, Toronto, Ontario, M5S 1B2. Phone: 416-323-6008; Fax: 416-323-6307; E-mail: angle@ ftn.net

The Women's College Hospital Department of Anaesthesia Research Fund was used partly to support this study. 
OSTDURAL puncture headache (PDPH) is the most important common complication of unintentional dural puncture ${ }^{1}$ during epidural placement. Obstetrical patients represent a high risk population with an incidence of PDPH of $70-85 \%{ }^{2-3}$

Active bearing down during the second stage of labour causes a marked increase in cerebrospinal fluid pressure (CSF). ${ }^{4}$ This may lead to greater loss of CSF through larger gauge dural holes and subsequent increased risk of PDPH and need for treatment. The purpose of this study was to examine the incidence of PDPH and EBP in patients with well-documented single dural punctures with a 17 gauge Hustead epidural needle as they relate to active bearing down and duration of pushing in parturients.

\section{Methods}

After hospital Research Ethics Board approval, a retrospective chart review was performed of 60 patients identified with unintentional dural punctures (UDP) in our institutional clinical database (since its inclusion) over three years. This database contains information, including anesthetic morbidity, on all births at Women's College Hospital during that time. Data are entered immediately after delivery. The database has been previously shown to have $>90 \%$ sensitivity for dural puncture. ${ }^{\mathrm{a}}$

The anesthetic records were reviewed independently by two staff anesthesiologists to verify first, that dural puncture had occurred and second, that the dural puncture had a high likelihood of being single as was reported on the anesthetic record. Patients included in the study were those in whom a single dural puncture was noted with an unequivocal report of "+CSF" flow or "dural puncture" and in whom the epidural was repeated easily at the same or another vertebral level easily (by report) or without noted difficulty. Patients excluded from analysis fell into the following categories : "multiple punctures documented" ; "dural puncture unclear" (not clear if multiple punctures or no puncture at all had occurred as reported); "catheter-related" (possible catheter punctures or subdural catheters as suggested by the procedure notes and clinical course); and, the "no evidence of dural puncture" category.

The following data were recorded: maternal age, weight, parity, mode of delivery, occurrence of PDPH, incidence of EBP, and duration of pushing after UDP.

\footnotetext{
a Halpern SH, Lin S. Assessment of a method of gathering quality assurance data in obstetrical anaesthesia. Can J Anaesth 1993; 40: A53.
}

A PDPH was defined as a postural headache or neckache occurring after dural puncture and lasting for more than six hours. Medical records were examined independently by two staff anesthesiologists and one research/ experienced labour and delivery nurse to determine the presence or absence of PDPH. Duration of pushing was defined as the cumulative time in minutes that the patient was involved in active bearing down in second stage labour to delivery as determined from detailed labour and delivery nursing notes. These data were reviewed independently by one staff anesthesiologist and an experienced labour and delivery (research) nurse.

Patients were divided into two groups. Those who had pushed in second stage labour after dural puncture (Group 1) and those who had not (Group 2). Group 1 patients represented women undergoing spontaneous vaginal delivery, instrumental delivery (no attempt had been made to limit pushing) and patients who had pushed after UDP but ultimately delivered by Cesarean section. Group 2 represented patients who delivered by Cesarean section before full cervical dilatation had been achieved or second stage pushing had commenced.

The primary outcome was the incidence of patients receiving at least one epidural blood patch. The secondary outcome was the incidence of PDPH. Demographic variables and duration of pushing were summarized using descriptive statistics. A two-tailed Fisher's exact test was used as appropriate. A P value < 0.05 was considered statistically significant.

\section{Results}

Thirty-three patients were found to have well-documented single dural punctures with a 17 gauge Hustead epidural needle. The remaining 27 patients fell into the following categories: multiple document-

TABLE I Patient demographics

\begin{tabular}{lll}
\hline Characteristics & Group $1(n=23)$ & Group 2 $(n=10)$ \\
\hline Maternal age (yr) & $32.6 \pm 5$ & $33 \pm 4$ \\
Gestational age (wk) & $38 \pm 4$ & $38 \pm 3$ \\
Parity (median,range) & $0,(0-2)$ & $0,(0-2)$ \\
Height (cm) & $168.1 \pm 13.9$ & $159.6 \pm 5.3$ \\
Weight (kg) & $58.25 \pm 5.2$ & $58.7 \pm 10$ \\
\hline
\end{tabular}

Mean $\pm S D$, (range)

TABLE II Relationship between bearing down and incidence of PDPH and EBP

\begin{tabular}{llll}
\hline Outcome & Group 1 & Group 2 & $P$ \\
\hline PDPH (yes) & $17 / 23$ & $1 / 10$ & $<0.002$ \\
EBP (yes) & $13 / 23$ & $0 / 10$ & $<0.002$ \\
\hline
\end{tabular}


TABLES IIIA, IIIB Relationship between mode of delivery and occurrence of PDPH and EBP by Groups

\begin{tabular}{lll}
\hline III a. Group $1(\mathrm{n}=23)$ & & \\
Mode of delivery & $P D P H($ yes $)$ & $E B P(y e s)$ \\
\hline SVD $(\mathrm{n}=17)$ & $11 / 17$ & $11 / 17$ \\
Instrumental delivery $(\mathrm{n}=5)$ & $5 / 5$ & $2 / 5$ \\
Cesarean delivery $(\mathrm{n}=1)$ & $1 / 1$ & $0 / 1$ \\
III b. Group 2 $(\mathrm{n}=10)$ & & \\
Mode of delivery & & \\
\hline SVD $(\mathrm{n}=0)$ & $P D P H$ yes & $E B P$ yes \\
Instrumental $(\mathrm{n}=0)$ & $0 / 0$ & $0 / 0$ \\
Cesarean delivery $(\mathrm{n}=10)$ & $0 / 0$ & $0 / 0$ \\
\hline
\end{tabular}

*SVD = spontaneous vaginal delivery.

†Instrumental delivery = low vacuum, low and mid-forceps deliveries.

ed punctures (8); catheter-related (6); unclear category (12) and no documented dural puncture (I) and were excluded from analysis.

Maternal age, height, weight, parity, and gestational age did not differ between pushing (Group 1) and non-pushing (Group 2) patients (Table I). Two patients with unintentional dural punctures developed immediate postural headaches after subsequent epidural attempts using loss of resistance to air techniques. In both cases the headaches resolved within two hours without recurrence. These patients were presumed to have air headaches and were assigned to the non-PDPH category.

One patient in the PDPH category had postural neckache only, relieved by one epidural blood patch. One patient in the pushing group (Group 1) developed PDPH severe enough to warrant EBP according to the authors' beliefs but did not receive one and was therefore analyzed as part of the non-EBP group.

Seventy-four percent of Group 1 patients (17/23) developed PDPH compared with $10 \%(1 / 10)$ in Group $2(P<0.002)$ (Table II). Fifty-seven percent $(13 / 23)$ of Group 1 patients received an EBP compared with none $(0 / 10)$ in Group $2(P<0.002)$ (Table II). The mean time of pushing in those who received EBP (13) vs those who did not (4) was $44.8 \pm 30 \mathrm{~min}$ ps $87.8 \pm 54$ min. If the one patient who was believed to warrant EBP but did not receive one is included in the EBP group the length of time pushing in those receiving EBP was $52 \pm 38 \mathrm{~min}$ vs $68 \pm 45 \mathrm{~min}$ in those who did not. None of the patients in Group 2 received an EBP.

Patients were also examined by mode of delivery within each group. In Group 1 (Table IIIa), 65\%

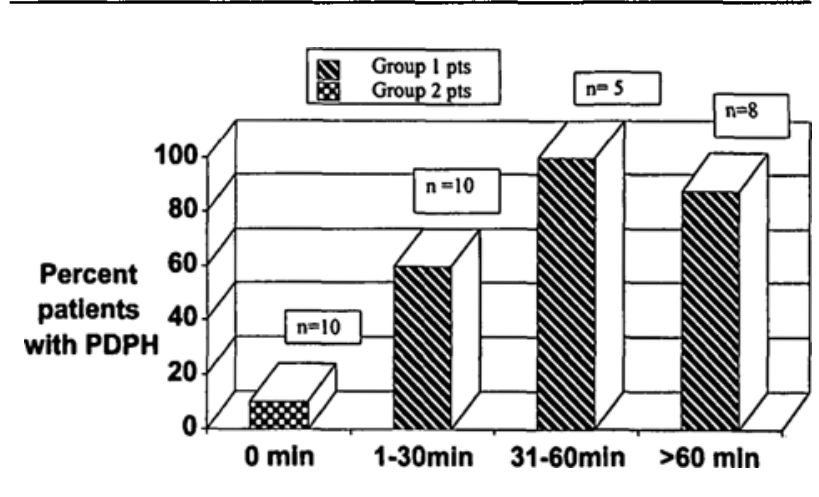

FIGURE Incidence of PDPH with cumulative duration of second stage pushing after dural puncture in minutes.

(11/17) of women with spontaneous vaginal deliveries developed PDPH with $100 \%(11 / 11)$ of those with headache receiving EBP. Similarly, $100 \%(5 / 5)$ of women delivering by outlet forceps, vacuum or midforceps developed PDPH with $40 \%(2 / 5)$ receiving EBP (Table IIIa). Only one patient in this group had a Cesarean section. The patient developed PDPH but did not receive an EBP. The majority of women pushing $>30$ min developed PDPH (Figure).

In Group 2 (Table IIIb), all of the patients delivered by Cesarean section. Only one patient $(1 / 10)$ developed PDPH and did not receive an EBP.

\section{Discussion}

Post dural puncture headache is related to loss of CSF volume. ${ }^{1,5}$ Factors that increase CSF leak such as increased needle size and tip design have been shown to have a profound influence on the incidence of PDPH. ${ }^{6}$

While obstetrical patients have long been thought to be at higher risk for developing PDPH after dural puncture than are non-pregnant patients, ${ }^{3}$ the reason for such a difference has not been apparent. Postulated etiologies have included increased loss of CSF through the dural puncture site due to expulsive efforts at delivery. While the additional amount of CSF loss may not be large enough in itself to produce headache, this loss, coupled with continued leak of CSF after delivery ${ }^{7}$ may be enough to reach a critical threshold of intracranial CSF volume reduction that triggers PDPH. The concept that a critical threshold volume reduction in intracranial CSF must develop before PDPH occurs is supported clinically by the usual delay in presentation of classic headache, as well 
as the variable occurrence of PDPH despite documented dural punctures with large gauge needles. The idea that a threshold in intracranial volume reduction exists is supported both by older as well as more recent human investigations. Original work done by the neurologist Fay $(1940)^{8}$ to evaluate the mechanisms of headache of unknown etiology explored the inter-relationship between patterns of intracranial intravascular reactivity to changes in artificiallyinduced changes in CSF volume in patients with a history of headache. While the information derived from this study is limited in its application to the pathogenesis of chronic headache in most individuals, the results provide valuable information related to postdural puncture headache.

Fay's study involved drainage of CSF to the point where patients complained of headache. Then, CSF was readministered with additional normal saline revealing an intermediate zone of CSF volume associated with patient comfort.

Further administration of normal saline produced headache at the other (high volume) end of the spectrum. Fay found that patients developed predictable patterns of headaches at high and low volumes of cerebrospinal fluid volumes and that varying thresholds for headache development were related to patient body habitus (normal, overweight and underweight). Fay's results support the idea that a critical intracranial volume reduction of CSF is necessary for producing postdural puncture headache and that the triggering threshold for headache varies among individuals. These findings correlate with the clinical experience that PDPH occurs less commonly in obese individuals and with the clinical impression that underweight individuals may be more at risk for PDPH after dural puncture.

A recent prospective neuroradiological study ${ }^{9}$ using Magnetic Resonance Imaging (MRI) also suggests that individual thresholds in CSF intracranial volume reduction play a role in PDPH. Intracranial CSF volume was imaged prior to lumbar puncture and after development of PDPH. The study showed that some patients developed PDPH after only a small volume of measured intracranial CSF volume loss. In other patients, an increasing incidence of PDPH (of increasing severity) was demonstrated with increasing intracranial CSF volume reduction. Most patients developed PDPH with $20 \mathrm{ml}$ CSF volume loss, the same volume of CSF loss associated with PDPH demonstrated by Kunkle, Ray and Wolff ${ }^{5}$ during deliberate withdrawal of CSF in human volunteers. Thus, while factors related to needle size and tip design likely play the predomint role in determining the incidence of $\mathrm{PDPH},{ }^{6}$ the additional CSF loss imposed during second stage labour coupled with leak during and after dural puncture may allow patients to reach their individual thresholds of intracranial CSF volume reduction and develop PDPH.

Previous authors have addressed the issue of bearing down and risk of development of PDPH. Ravindran et al. ${ }^{10}$ prospectively randomized patients to spontaneous vaginal delivery or elective outlet forceps following saddle block with a 22 gauge spinal needle placed at the time of crowning of the fetal head. The authors were unable to demonstrate a difference in the rate of development of PDPH, probably because of the small sample size as well as other factors such as the relatively small dural hole and the likely short duration of expulsive efforts given the timing of administration of the block (length of time pushing was not noted).

Stride et al. ${ }^{11}$ retrospectively examined the charts of obstetric patients receiving epidural analgesia from 1969 to 1988. Four-hundred and sixty accidental dural punctures were identified. The incidence of PDPH was examined in patients receiving a variety of therapies including epidural bupivacaine $0.5 \%$ and elective instrumental delivery after unintentional dural puncture. These patients were urged not to push during instrumental delivery. No differences in PDPH were found between those receiving heavy epidural blocks and those allowed to push to delivery after dural puncture. Changing practices in management of these patients over this time, inability to control for patient bearing down while waiting for local anesthetic to take effect or variations in analgesia and hydration may have contributed to this finding. Interestingly, the authors noted a subgroup of Cesarean section patients who did not reach second stage labour. Unfortunately, this latter, more pure group of non-bearing down parients was not analyzed separately.

We compared patients with well-documented single unintentional dural puncture who had never engaged in active pushing after dural puncture (Cesarean section patients delivering before second stage labour) with parturients who had pushed for delivery and measured the cumulative time pushing in second stage labour until delivery. We chose to study well-documented single dural puncture because the incidence of PDPH after multiple puncture is not known but likely to be higher and might confound our results.

Patients in whom catheter-related puncture seemed likely were excluded since smaller diameter puncture would be expected to have a lower the incidence of PDPH. ${ }^{6}$ We recognize that some of these latter patients may have had unrecognized dural punctures/tears with the epidural needle.

Given the retrospective nature of this study, we recognize the potential for bias as we depended on the 
procedure notes of the anesthesiologist involved to identify patients mostly likely to have only single punctures. We believe, however, that the women analyzed as single punctures in this study represent a sample of patients in whom only single puncture occurred with high likelihood. In addition, even if studied prospectively, issues related to the absolute certainty of single $p s$ multiple dural punctures or full puncture $v s$ a small tear would still remain an issue imposed by the blind nature in which epidurals are usually performed.

The incidence of PDPH reported in Group 1 (74\%) is consistent with that in the literature. ${ }^{12}$ The somewhat lower overall incidence of PDPH (55\%) in the combined study groups likely reflects the relatively large number of patients in the non-bearing down category in our study sample and obstetric practice in a tertiary obstetric hospital. While milder headaches may have been under-reported, since these data were taken from nursing and physician clinical notes and not from an objective standardized questionnaire, we doubt that patients with postural headaches would have escaped detection. In addition, there is always the possibility that patients may have developed PDPH after discharge from hospital and sought care elsewhere, thereby escaping detection. Again, this seems unlikely and should not differ between groups. Hence, while some patients may have been missed, this should not bias the results.

We are not surprised that our pushing population had an incidence of PDPH similar to that reported in other studies, since we would not expect this population to have pushed longer or harder after dural puncture than women in other studies where no effort was made to minimize bearing down. The major finding in this study is the low incidence of headache and EBP in the non-pushing population (Group 2) compared with those who pushed. While our findings may reflect the small sample size or the criteria for inclusion that we used for PDPH, since some patients with mild nondiagnostic headache or transient air headache were assigned to the non-headache category, we doubt that these factors can fully account for the degree of reduction in PDPH and EBP found between Groups 1 and 2 since similar patients would have also been excluded from the headache category in Group 1. If Group 2 patients with mild non-diagnostic headaches (2) are included in the headache group the incidence of PDPH would be $30 \%$. If the two patients with clear transient air headache symptomatology are also included, the incidence of PDPH would be $50 \%$. We note these findings to illustrate the need for defining inclusion criteria for PDPH in future studies.

Other factors have been thought to play a role in the incidence of PDPH. These include patient hydra- tion, bed rest technical aspects of needle placement, use of neuraxial opioids and prophylactic epidural volume (blood, dextran or normal saline).

Typical instructions given to patients at our hospital following dural puncture include advice to maintain oral hydration (including caffeinated beverages) avoidance of straining and the addition of a stool softener to the postoperative medical regimen. There is no standard hydration protocol since intravenous hydration following dural puncture has not been shown to prevent PDPH in patients who are able to maintain normovolemia. ${ }^{13}$ Patients undergoing epidural anesthesia are typically fluid loaded with $1000-1500 \mathrm{ml}$ Lactated Ringer's solution and given crystalloid for fluid maintenance and blood loss replacement. After delivery, patients (both vaginal delivery and Cesarean section) typically receive Lactated Ringer's solution at a rate of $125 \mathrm{ml} \cdot \mathrm{hr}^{-1}$ for six to eight hours with oxytocin $\left(20 \mathrm{u} \cdot \mathrm{l}^{-}\right.$ 1) and are encouraged to drink fluids as soon as possible with the intravenous infusion being discontinued at that time. Early ambulation is encouraged since prolonged bed rest has been shown to delay, not prevent, the occurrence of PDPH. ${ }^{14}$

Needle orientation at the time of dural puncture may have a impact on PDPH incidence. ${ }^{15}$ While our staff are well-aware of these findings we are not able to comment on the role that needle bevel direction may have had in this study given its retrospective nature and the lack of specific mention of this technical aspect in the procedure notes. In addition, recent authors ${ }^{16}$ have commented on the potential role that failure to reinsert the stylet prior to withdrawal of the needle may play on the incidence of PDPH after dural puncture with spinal needles. Since reinsertion of the stylet after UDP with the epidural needle has not been a common practice at our hospital, especially during the period (April, 1995 to January, 1998) in which data were collected, we do not believe this practice had any impact on our results.

The parients in our study all received conservative postpartum management including opioid and nonnarcotic analgesics and variable administration of a non-steroidal anti-inflammatory drug (naproxen or ibuprofen). None of the patients in this study received what we would consider non-conservative prophylactic therapy, namely: serotonin agonists, intravenous adrenocorticotrophic hormone (ACTH) or epidural administration of normal saline, dextran, or autologous blood. Likewise, none of the patients received epidural infusions for pain relief postoperatively.

The incidence of EBP in patients with PDPH $(72 \%)$ in our study is consistent with that described elsewhere in this patient population. ${ }^{17}$ The lack of cor- 
relation of the incidence of EBP with the incidence of PDPH likely reflects variations in thresholds of anesthesiologists to administer EBP, patient willingness to receive EBP and possible lessening of severity of symptoms over time. The lack of correlation between EBP and length of time pushing may simply reflect the small sample size involved. It also suggests that receipt or failure to receive an EBP is not necessarily a good indicator of the severity of PDPH.

Despite the limitations imposed by the retrospective nature of this study, the markedly lower incidence of PDPH and EBP in patients who never engaged in active pushing after dural puncture compared with those who pushed suggests that bearing down in labour may impact on the incidence of PDPH and EBP.

\section{Conclusions}

Active bearing down in second stage labour after welldocumented single 17gauge dural punctures is associated with a higher incidence of PDPH and EBP when compared with the incidence of these outcomes in parturients who never pushed for delivery. There may also be a time-dependent association between the cumulative duration of bearing down in second stage labour and the incidence of PDPH.

\section{Acknowledgments}

The authors thank Dr. Rose Kung and Dr. Jon Barrett, Department of OB/GYN at Women's College Hospital for their review of the manuscript and helpful advice. We would also like to thank the Department of Medical Records and the Medical Library staff at Women's College Hospital for their dedicated assistance in this study.

\section{References}

1 Wulf $H F W$. The centennial of spinal anesthesia. Anesthesiology 1998; 89: 500-6.

2 Gielen $M$. Post dural puncture headache (PDPH): a review. Reg Anesth 1989; 14: 101-6.

3 Vandam $L D$, Dripps $R D$. Long-term follow-up of patients who received 10,098 spinal anesthetics. JAMA 1956; 161: 586-91.

4 Marx G, Zemaitis MT, Orkin LR. Cerebrospinal fluid pressures during labor and obstetrical anesthesia. Anesthesiology 1961; 22: 348.

5 Kunkle EC, Ray BS, Wolff HG. Experimental studies on headache. Analysis of the headache associated with changes in intracranial pressure. Archives of Neurology and Psychiatry 1943; 49: 323-58.

6 Halpern S, Preston R. Postdural puncture headache and spinal needle design. Anesthesiology 1994; 81 : 1376-83.
7 Kadrie $H$, Driedger AA, McInnis W. Persistent dural cerebrospinal fluid leak shown by retrograde radionuclide myelograph: case report. J Nucl Med 1976; 17: 797-9.

8 Fay T. A new test for the diagnosis of certain headaches: the cephalalgiogram. Dis Nerv System $1940 ; 1: 312-5$.

9 Grant $R$, Condon B, Hart I, Teasdale GM. Changes in intracranial CSF volume after lumbar puncture and their relationship to post-LP headache. J Neurol Neurosurg Psychiatry 1991; 54: 440-2.

10 Ravindran RS, Viegas OJ, Tash MD, Cline PJ, Deaton $R L$, Brown TR. Bearing down at the time of delivery and the incidence of spinal headache in parturients. Anesth Analg 1981; 60: 524-6.

11 Stride PC, Cooper GM. Dural taps revisited. A 20 year survey from Birmingham Maternity Hospital. Anaesthesia 1993; 48: 247-55.

12 Brownridge $P$. The management of headache following accidental dural puncture in obstetric patients. Anaesth Intensive Care 1983; 11: 4-15.

13 Dieterich $M$, Brand T. Incidence of post-lumbar puncture headache is independent of daily fluid intake. Eur Arch Psychiatry Clin Neurosci 1988; 237: 194-6.

14 Carbaat PAT, van Crevel H. Lumbar puncture headache: controlled study on the preventive effect of 24 hours' bed rest. Lancet 1981; II: 1133-35.

15 Norris $M C$, Leighton $B L$, DeSimone $C A$. Needle bevel direction and headache after inadvertent dural puncture. Anesthesiology 1989; 70: 729-31.

16 Strupp M, Brandt T. Should one reinsert the stylet during lumbar puncture? (Letter) N Engl J Med 1997; 336: 1190.

17 Hunter GJ, Fogel ST, Holtmann B. Accidental dural puncture in obstetrical patients: the failure rate of $\sin$ gle epidural blood patch. Society for Obstetric Anesthesia and Perinatology 1996; Al88. 